\title{
Video games: flagships of digital colonialism or solitary beacons of creative freedom and diversity? 1
}

Try suggesting that video games might be capable of leading the way towards a better future and see what happens. It is unlikely to prove to be a popular view. There are, after all, so many problems in the here and now. Once the ills are catalogued, any remotely optimistic conclusion is seen as a fever dream by colleagues and classes.

Let us count the ways:

- Rampant misogyny through in-game stereotyping of virtual women and often open discrimination of actual women in the industry.

- Toxic environments (in game and outside on Twitch and YouTube) where harassment and cyberbullying often targeting women and minorities are widespread.

- Aggressive monetisation techniques and targeted addiction as content, especially on mobile devices. It is no surprise that the video game equivalent of closely gated Skinner Boxes can make money through mass victimization. At a certain speed, the hamster wheel inevitably falls off its moorings.

And yet ...

More people are playing video games than ever before. Pick your reasons, but there are much more compelling ones than addiction or placebo sexuality. Video games have never been better, more open in design, or more solicitous of player interaction and creativity. The post-structural nature of video games allows people to come together on their own terms and in communities of their own choosing. Video games are truly fun as long as you can route around behaviourist boredoms and repetitive tropes. And women have become equal partners in the gaming universe by any measure you wish to choose, including sheer fast-twitch abilities.

It is not without reason that digital media has only strengthened western colonialism of cyberspace. In particular, the ever-increasing commercialization of the internet, coupled with the power of target advertising through Facebook and its brethren, and spiced up with the 'Influencer' culture, all seem designed to promote western dominance. Is there any other culture but internet culture? And what roles do video games play? They are, the story goes, merely cultural artifacts of western cultural hegemony perpetuating those self-same techno-libertarian values while manipulating the subconscious of new gaming generations to be harvested Matrix-like for their lifeenergy so that the batteries of western corporate giants can be fed ...

Except ...

Video games began in earnest in the 1970s from largely iconoclastic roots. As such games are at least somewhat behind the curve in having evolved as a self-serving form, Hollywood style, where financing and distribution systems only create and carry what they are meant to. Pong, Tetris, Pac Man, Asteroids ... if there really is a subconscious western ideological message to the origin stories of video games, do tell. More recent games like Minecraft and The Outer Worlds remind us that the promise of video games is that they could be about anything at all and you, as a player, can be an integral part of that freedom. Whatever may be said, video games are certainly not a medium restricted by a cultural hegemony. Every open world architecture, every massively multiplayer possibility, and every design feature that hands the storytelling to the player, potentially moves the game itself further and further away from the familiar gravitational pull of western colonialism and its idioms. In fact, the post-structural nature of games encourages designers to facilitate individual choice and creativity not very colonialist after all. The game industry seems to remain, for better and worse, much more aligned with creative choices than hidden cultural messages.

While, all the while, the industry grew, and grew, and grew ...

Can video games offer a viable structural model to fend off digital colonialism? Possibly. On this point here is a riddle meant to amplify our analysis of the question:

Q: What do AOC playing Among Us on Twitch; Sony's PS5, and Tencent's successful legal action against the makers of Crises Action have in common?

A: Absolutely nothing. Therein lies the point.

Perhaps equally clarifying of the point is this particularly international, diverse and manifestly non-colonialist issue of the Interactive Entertainment Law Review, we are proud 
to publish a selection of articles challenging the underlying infrastructure. The first article 'Aren't we all exhausted already? EU copyright exhaustion and video game resales in the Games-as-a-Service era' by Alina Trapova and Emanuele Fava wrestles video games as complex digital products away from often one-dimensional distinctions between ideas and expressions, goods and services. In 'Freedom of information, right to express and social media in India' Meera Mathew anchors social media and interactive entertainment back to its democratic foundations. Anna Vvedenskaya recognizes the importance of user participation and network effects for the value creation process in the video game industry and brings us a truly unique tax law perspective in 'Common features of video games and social networks: importance for international taxation'. In 'Copyright law issues in the context of video game Let's Plays and livestreams' Anna-Lisa Tie shines light on the impact of copyright and techno-solutionism on user creativity in Let's Plays and livestreams. Nick Kempton takes us through the copyright perils and opportunities of Brexit in 'Interaction of EU and UK copyright in a Post-Brexit world: will video games get more protection than they bargain for?'. And finally, we close this issue with Danae Balcells Moline's article 'My face is yours: facial recognition software and copyright ownership', which looks at how the use of technology can push legal and ethical considerations to a breaking point.

Moving from post-structural to the manifestly structural, we are also extremely happy to announce that Dr Yin Harn Lee from the University of Bristol and Dr Michaela MacDonald from Queen Mary University of London have joined our editorial board. Their expertise and dedication have already been of great impact on this issue, and their work will significantly benefit the readership of IELR and our wider community. Please join us in welcoming them!

Dr Gaetano Dimita Professor Jon Festinger Q.C. Dr Yin Harn Lee Dr Michaela MacDonald Dr Marc Mimler 